\title{
Priorities for Sustainable Urban Development as Exemplified by Individual Asian Countries
}

\author{
Marina Ermolina ${ }^{1 *}$, Anna Matveevskaya ${ }^{1}$, Daria Matyashova ${ }^{1}$, and Natalia Kovalevskaya ${ }^{1}$ \\ ${ }^{1}$ St. Petersburg State University, 199034, 2 Mendeleev line, St. Petersburg, Russian Federation
}

\begin{abstract}
Studies have shown that comparison of strategies for sustainable cities in Asian countries is carried out through the prism of the international concept of sustainable development. The work builds a complex relationship between general and specific criteria for sustainable development of the urban environment in the strategies of individual Asian countries. Priority is given to management, socio-economic development, and environmental protection. Sustainable urban development guidelines are shown considering problems of poverty, environmental pressures, and drawing attention to environmental problems in cities. The particular countries (Bhutan, Myanmar and Cambodia) show guidelines for sustainable urban development, considering urbanization and population flows, the vulnerability of major population groups and addressing poverty and pressure on the environment. Analyzing the Sustainable Development Goals and internal strategies of Asian countries, the authors sought to determine the goals and objectives of creating sustainable cities, features of sustainable cities' strategies in individual Asian countries and typical problems that arise on the path to sustainable urban development. The hypothesis of the study is the approach to sustainable cities through the prism of the concept of sustainable development with its socioenvironmental and economic components in their relationship and interdependence.
\end{abstract}

\section{Introduction}

Academic and environmental communities began to formulate the theoretical concept of sustainable cities in the 1990s. The discussion is whether a city can be considered a system compatible with sustainable development. For example, Peter Berg, as an eco-activist and founder of the Planet Drum Foundation, an environmental organization, said that cities could not be considered sustainable. Cities depend on the supply of energy and products from afar, which in turn provokes emissions due to transportation and threatens natural biogeocenoses. Since the city as a system did not claim to be in a state of sustainability, it had to be made "green" - that is, to ensure waste disposal and create links with natural ecosystems (Berg), to delegate new functions to the city for the conservation and

${ }^{*}$ Corresponding author: ermolinama@gmail.com 
reconstruction of the natural environment (Leff), harnessing its economic and social resources for the above purposes in full (Mayir) [1].

This multi-pronged approach has influenced the inclusion of the city in the concept of sustainable development. This is due to solving the problems of economic and social strategies for sustainable development, means of "greening" the city, as well as maintaining the viability of the urban system. In one of the first scientific papers on this subject - G. Hoton and S. Hunter "Sustainable cities" (1994), it is written that a sustainable city is "a place where its people and their associations constantly make efforts to improve the components of nature and environmental culture at local and regional levels" [1]. This work attempted to conduct a holistic and comprehensive analysis of the criteria for urban sustainability. The authors' attention was focused on the growth of cities, the consumption of such resources as agricultural products and clean water, and, as a result, pollution intensification. The main recommendations for achieving sustainability were: changes in the size of cities, their population density, as well as the reconstruction of transport infrastructure and housing in order to achieve "internal orderliness" [1].

These recommendations turned out to be too general and received their detailed consideration in the work "Urban agriculture: food, employment and sustainable cities". The work was published in 1996 as part of the Second United Nations Conference on Human Settlements (Habitat II). The research of Jack Smith, Joe Nasr, and Anna Ratt, conducted under the auspices of UNDP in 1991-1992, provided knowledge-based empirical material. The authors analyzed sustainable cities, focusing on the problems of food security and environmental safety of consumed products. The authors believe that the degradation of the biosphere can be stopped by transferring agricultural production to cities. Sustainability of the city is determined by the ability of its residents to conduct sustainable agriculture using small land areas, waste-free management, and reducing transportation costs [2]. D. Satterwater's work, "Sustainable Cities or Cities Contributing to Sustainable Development," provides broader recommendations on how cities can become actors to solve sustainable development issues [3].

The management factor in the issue of sustainable urban development is covered in the paper "Managing Sustainable Cities". B. Evans, M. Joas, S. Sandback and K. Theobold analyzed examples of 40 cities of the European Union and expressed the following points:

- governance and local government are key elements of sustainable urban development;

- elements of global civil society are drivers of quality management of a sustainable city of social capital and partnership;

- partnerships operate on the basis of their institutional capital, which operates most efficiently under conditions of dynamism and democracy [4].

The relationship between quality management, economic growth, and the environment was more clearly delineated in the work "Sustainability and Cities" by Lin Gyok Oo. Note that the study touches upon a rare perspective of sustainable development in megacities in the developing world. The author believes that the relationship between responsible consumption and the environment in the framework of sustainable development was modeled on the example of cities in developed countries [5]. However, these patterns did not help solve local problems, which exacerbated the vulnerability of certain population groups.

A new trend in development of the concept of a sustainable city is based on idea of "smart city", which has been emerging since the early 2010s. "Smart cities" are the result of the meaningful use of digital information according to the work of Deakin and Al Waer (2012), as well as Townsend (2013): for example, in areas such as human health, mobility, energy use, education and urban governance [6]. J. Wrangel notes that the concept of a smart city has not yet been fully formulated and therefore it is still difficult to integrate into 
a detailed concept of sustainable development [7]. It should be noted that some researchers consider the possibilities of the "smart city" as an integral element of achieving sustainability [8], while other researchers note a non-linear relationship between the use of technologies for collecting information and solving environmental problems.

\section{Sustainable cities: characteristics of long-term and short-term development models}

The task of creating safe, open human settlements remains a priority within the global strategy for sustainable development. It is currently included in sustainable development goal No. 11. However, its incorporation into the agenda for achieving economic, environmental and social balance on a global scale began in 1987 with the report of the commission H. H. Bruntlandt "Our Common Future" [9].

The UN Conference on Sustainable Development, held in 1992 in Rio de Janeiro, reinforced Bruntlandt's call for municipalities and local governments to strengthen partnerships with the private sector to realize the goals and objectives of Agenda XXI. However, the agenda itself focused more on the challenges and threats posed by the cities themselves, rather than their ability to tackle sustainability issues. In particular, it was mentioned that "urban growth leads to environmental degradation, thereby creating a serious danger to the population" (chapter 6), that "in industrialized countries, urban consumption patterns create an excessive burden on the global ecosystem" (chapter 7) that urbanization provokes the problems of water exhaustion due to the increased need to provide water supply and sanitation to cities (Chapter 18) [10]. Nevertheless, as H. Bulkley and M. Betsill write, the adoption of Agenda XXI. accelerated large-scale activity at the level of municipalities around the world [11].

Economic stability is achieved through the formation of agglomerations, in which stable labor flows between the urban center and rural suburbs are created on the basis of seasonal pendulum migration. Permanent trade and economic relations and flow of capital and profits are becoming an important feature of such interdependent systems. The middle class is interested in consuming products produced in the suburbs. This leads to a flow of funds to the suburbs and reduce inequality [12]. In turn, higher incomes for suburban residents guarantee access to quality education and healthcare.

The creation of "smart cities" is the most promising and productive mechanism in terms of protecting the environment. This mechanism involves high-tech environments, united by infrastructure projects and information flows in the framework of network interactions. These environments can improve energy efficiency, monitor the consumption of goods, water and air quality, control the process of waste collection and disposal, contribute to improving housing conditions and health protection, and optimize traffic, thus regulating such an important parameter as, for example, air quality [13]. These trends characterize the city as a sustainable environment in the long term.

In the short term, the formation of agglomerations is associated with the risks of a largescale influx of labor, which can lead to unemployment. Unemployment, in turn, leads to an increase in inequality on the one hand and the emergence of polar identities "urban residents" on the other. In the context of ethnic and religious heterogeneity, this situation is associated with the risk of conflicts that slow down the formation of identities of urban communities, further stimulated by progressive deprivation. If urban communities are not consolidated, the central authorities can either take measures to limit immigration to the city, which reinforces the inequality between the city and the countryside, or create infrastructure and institutions without considering the needs of the urban community. 
The influx of employees and their families into the city leads, on the one hand, to an intensification of consumption of essential goods and services, on the other hand, creates a demand for higher-quality goods, simultaneously changing the rhythm of demand. Intensification is associated with an increase in the amount of waste and at the same time with the exhaustion of resources, especially clean water and soils, especially in the agricultural sector. The intensity of production cycles in agriculture is associated with the use of biotechnology - improved highly productive varieties, fertilizers, etc. The "Green Revolution" of 1950-1960s is an example of the success of this approach. It was a globally coordinated effort to transfer the latest agricultural technology — hybrid seeds, fertilizers, pesticides, irrigation technologies - from developed countries to the developing world [14].

The result was the opportunity to avoid the "Great Asian Famine" projected in the $1950 \mathrm{~s}$. However, growth in cereal yields fell to $1.3 \%$ by the early $2000 \mathrm{~s}$, while the population continued to grow. In addition, the "green revolution" exacerbated poverty, as wealthy landowners gained access to agro-technology at the expense of the poorest farmers [14]. The introduction of new technologies for the collection and processing of information (big data) to improve the quality of life and improve waste disposal requires, firstly, the existence of a well-functioning data security system, secondly, guarantees of privacy and protection from administrative pressure for citizens, and thirdly, infrastructure for waste processing and energy conservation, otherwise the usefulness of "smart cities" is limited by the socio-economic aspect. The meta-objective of sustainable urban development is to minimize the damage to social equality, infrastructure and the environment in the short term, to ensure a smooth transition to stable systems with normalized, self-regulating migration flows and balanced interaction with the environment.

\section{Features and problems of sustainable urban development in Asian countries}

A dual situation developed in Asian countries in the 1990s-2000s. On the one hand, cities are becoming a "sphere of prosperity" [15], attracting labor force and foreign capital, interested in using natural and human resources in conditions of accelerated urbanization. This made it possible to raise funds for the construction of housing, the creation of water supply networks and waste disposal. On the other hand, intensive development was understood as an increase in economic sphere and the number of attracted investments. This had led to neglect of the urban environment. The aggravation of the situation is associated with poor coordination of intergovernmental agencies, lack of feedback between municipalities and central government bodies, poor-quality expertise for competent urban planning [16]. The key challenges for sustainable urban development in the Asian region were: high centralization of government, increased vulnerability to natural disasters as a result of intensified economic activity, and the spontaneous expansion of suburbs, which contributed to the emergence of slum-like satellite towns around the agglomeration centers that threatened the safety of the agglomeration [15].

The reasons for this situation are the increasing importance of cities in the income structure of Asian economies. This applies to both the "Asian tigers" and the middle- and underdeveloped countries. The report by M. Lindfield, "Challenges for the Sustainable Development of Asian Cities," states that, firstly, there is a rapid population growth (about $3 \%$ per year - M. Lindfield) [17], and secondly, an increase in the load on electric networks and the atmosphere. 
11 of the 20 most polluted cities in the world are located in Asia. In many Asian countries, traffic congestion losses account for $5 \%$ of gross domestic product. Short-term economic growth is becoming one of the reasons for rising sea levels due to rising temperatures, declining population health, and weakening ecosystem sustainability in the long run [18]. Another reason for the deterioration of the environmental situation was an attempt to compensate for the need for electricity and fuel in an extensive way. The exhaustion of coal, oil and gas resources, the construction of thermal power plants and hydroelectric power stations led to a reduction in acreage and destruction of biocenoses of reservoirs.

D. Kenworthy's empirical research on the issue of emissions from motor transport showed that instead of a strategy for universal motorization, cities choose strategies to expand the use of small-scale motor transport and intensify rail traffic (Taipei), increase the number of non-motorized vehicles (Shanghai, Guangzhou, Beijing, Mumbai) or develop public transport networks (Sao Paulo) [19]. Empirical data obtained by world Bank researchers show that as the urban population grows from 16 to 48 people per hectare, fuel consumption per capita decreases. Thus, "growth dictates a strategy" for creating energyefficient, low-cost transportation networks.

The creation of such networks requires material resources, which should be available to the community of citizens, or urban government and planning bodies integrated into a centralized system. ESCAP estimates that developing countries in the Asia-Pacific region should invest an additional $\$ 1.5$ trillion annually if they wish to achieve the Sustainable Development Goal by 2030. These investments should go to social and environmental infrastructure (educational and health facilities, water supply, sanitation facilities, organization of protected areas, development of alternative energy) [20]. At the same time, most of these benefits will be placed in cities.

Nevertheless, Asian countries still lack investment, which, according to estimates by the Asian Development Bank, is $\$ 460$ billion. This is less than half of the investment need to maintain the socio-ecological balance in the settlements of the region [20]. The reason for the lack of funding for socially and environmentally significant projects is the imperfect and non-transparent principles of budget transfers from the private and public sectors. This is due to the high centralization of public administration systems, seeking to subordinate cities and their finances to tight control. This problem was significant and acute in the 2000 s and remains relevant to this day.

ESCAP experts in the report "The Future of the Asia-Pacific Cities-2019" offer to solve the problem of creating public-private partnerships in the field of financing socially significant projects and protecting the environment. They pay attention to the introduction of targeted taxes and fees, the development of a mechanism for generating income through the growth of land value. However, experts acknowledge that more serious forms of cooperation are needed through negotiations on larger transfers with ministries of finance [21].

Poverty is another issue for the sustainable development of cities and metropolitan areas in Asia. World Bank data for 2014 indicate that about $64 \%$ of the urban slum population is located in Asia. This is about 563 million people. The share of slum dwellers was particularly high in countries such as Mongolia, Myanmar and the Philippines. Here, these indicators range from 38 to 43 percent [22]. Poverty in cities is lower than in rural areas. For example, in India $13.7 \%$ of urban residents and $25.7 \%$ of rural residents live below the poverty line, in Indonesia - 6.7\% and 12.9\%, respectively, in Myanmar - 11.3\% and 30.2\%, respectively. However, urban poverty poses a threat, as intensive migration is associated with a lack of funding for social projects. Unemployment in the region remains low $(4.2 \%$ in 2018 - ILO), despite economic growth. A significant part of jobs in the region was 
created in "vulnerable sectors", which are characterized by unskilled and low-paid labor. According to ILO forecasts, $72 \%$ of workers in South Asia, 46\% in Southeast Asia and the Pacific, and 31\% in East Asia are workers in vulnerable sectors in 2019 [22].

Thus, typical problems for Asian cities in the field of sustainable development are the lack of feedback between urban communities and governing authorities; intensive population influx, leading to widespread urban poverty and increased energy consumption; violation of the ecological balance due to the growth of $\mathrm{CO} 2$ emissions into the atmosphere and destruction of ecosystems to expand the energy sector.

\section{Sustainable cities strategies in Asia's least developed countries}

Least-developed country tactics for resolving problems can be seen in the planning documents for sustainable development. The most illustrative examples in this regard are the three Asian least developed countries - Bhutan, Cambodia and Myanmar.

\subsection{Bhutan}

Bhutan is implementing the sustainable development goals in the framework of five-year socio-economic plans. The latest plan (for 2018-2023) [23] includes development steps. 17 Key national performance areas are articulated in this document. They are not identical to the 17 goals of sustainable development. For example, goal No. 11 (sustainable cities) is correlated with Key areas No. 4 (preservation of culture) and No. 5 (healthy ecosystems), which indicates the desire to achieve a balance between the environmental and social aspects of urban development. Goal 16 (Peace, Justice, and Strong Institutions) is not implemented in areas directly related to urban development. However, this does not mean that the issue of the formation of urban communities and civil society is ignored in the document, since Key Area 4 is related to the long-term goal of community viability, and Key Area 5 to effective governance.

Another indication of the desire to achieve balance in urban development is the emphasis on decentralization ("empowering local governments and other subnational bodies by giving them greater financial, planned and administrative responsibility, powers and guarantees of accountability") and on ensuring the viability of society. The section on urban development states that the task is to "increase the efficiency and effectiveness of municipal services". The implementation of these processes correlates with the solution of the typical Asian problem of weak communities and institutional barriers at the municipal level. At the same time, the authors of the document plan to correlate the sustainability of settlements with cultural diversity, which indirectly indicates a willingness to create inclusive communities and resolve conflicts in them.

There are no concrete measures proposed to address the problem of urban poverty in the five-year plan - this is due to,

- firstly, with the fact that urban poverty in Bhutan, according to the Analytical Poverty Report, is $0.8 \%$ [23];

- secondly, with the fact that most of the poor in the country (97\%) are concentrated in rural areas. Accordingly, it is not urban poverty itself, but inequality that threatens the sustainability of cities.

A measure to prevent urban poverty can be considered a program to create small and medium-sized enterprises in the countryside, expanding the network of advanced training 
courses and supporting target groups of people in need. This program has a "dual" purpose from the point of view of sustainable development, since, in addition to solving the problem of poverty, it strengthens the institutions of local administrations authorized to implement it.

The authors of the five-year plan see the main problem of the environmental balance, the transport system and the problem of car emissions. Unlike other underdeveloped countries, Bhutan focuses on expanding the use of information and computer technologies and media technologies in the transport sector, increasing the level of digital literacy which, in our opinion, indicates a solution not only of the country's exit from the group of least developed countries, but also the problem of building smart sustainable cities in the future. The directions of urban development are spelled out in the document, which is reflected in measures to introduce green technologies into urban construction, planting green spaces in cities, and creating recreational and sports zones.

The national Bhutanese strategy for formation of sustainable cities, described in the materials of the document, is not detailed, describing only the main directions of development and providing local administrations with most of the authority in determining the means and measures to achieve sustainable urban development.

This indicates the achievement of a significant level of independence of administrations and urban communities. However, the Bhutan five-year plan does not highlight measures to support the increased participation of civil society in the sustainable development of urban spaces and municipalities. Another drawback of the Bhutan plan is that it ignores the issue of choosing a transport development model in an urban environment. The development of environmentally friendly public transport is mentioned in two sections, but neither the choice of the trajectory of environmental development in conditions of increasing traffic density in cities, nor the aspect of the necessary infrastructure modernization in modern conditions is specified.

\subsection{Cambodia}

The concept of sustainable development is implemented in a number of documents adopted by the Government of Cambodia. The fundamental document is the so-called "Rectangle Strategy", covering the period of country's development from 1998 to 2023 [24]. At present, the fourth stage of the "Rectangle Strategy" is being implemented. The country focuses on effective governance, human resources development, economic diversification, and increased employment in the private sector. More specific recommendations are formulated in the National Strategic Development Plan, which includes the Sustainable Development Goals, the Long-Term Development Goals formulated in the Government Survey-2030, a roadmap for achieving Cambodia's status as an upper middle-income country, and in Survey-2050, in which Cambodia should move into the category of highincome countries [24].

Urbanization is not considered either a challenge or a threat in the rectangle Strategy document. This demonstrates that the authors of the document consider this process separately from the problems of increasing poverty, environmental degradation or increasing social inequality. On the contrary, the document prescribes theses about the "expected impulse of economic growth", about the growing middle class, about the fact that $85 \%$ of Asia's gross domestic product is produced in cities, it can be assumed that urbanization is perceived in a positive way in the Cambodian strategy for sustainable development. 
Sustainable development in Rectangle Strategy is related to a block of meta-goals. At the same time, the task of ensuring communication between local communities and the authorities should, according to the authors of the strategy, be solved within the framework of three other "rectangles". Thus, the authors propose, in order to increase the transparency of institutions, to plan "the expansion of publications of updated information on public services, legal documentation and documents on national policy", "encouraging citizen participation in the development process, as well as in the development and implementation of various strategies", in the framework of strengthening private sectors - "conducting research and preparing the fundamentals of a policy to strengthen corporate social and environmental responsibility" and "continuing the implementation of the state-cha dialogue". Corporate social responsibility contributes to the creation of communities that operate on the basis of horizontal and network principles, due to which, it is possible to exchange information and means most effectively, becoming the basis for sustainable selfgovernment. Declaring this in the "Rectangle Strategy" indicates that Cambodia not only does not ignore horizontal-network relations in civil society, but also seeks to shape them.

Transport and logistics in the Rectangle Strategy are considered solely in connection with the formation of a system of a sustainable economy, and not sustainable cities. So, according to the chapter on economics, road construction must be coordinated with urban planning - that is, urban development in this regard is considered a secondary factor. Also, as in Bhutan, the issue of choosing a model of transport development is ignored in conditions of intensive urbanization.

At the same time, the authors of the strategy, in the part devoted directly to urban sustainable development, acknowledge that inattention to infrastructure issues and a focus solely on planning in the field of land use and housing construction have already led to negative consequences. They mention that in large cities of the country, "the housing stock is in poor condition; roadside territories are illegally used; there are facts of an encroachment on natural objects - lakes, forests, and state lands that have been ignored; "urban transport and traffic are in poor condition, which leads to unjustified social and economic costs". For this reason, the current strategy for the sustainable development of cities is focused primarily on increasing their infrastructural power - in the areas of transport and logistics, namely, "the creation of pedestrian zones, parking spaces", "improving the quality and expansion of the use of public transport in the city" and utilities - "the development of electric networks, systems for providing clean water, especially sewage and water treatment systems". However, the issue of expanding the housing stock and the implementation of the affordable housing program are not being addressed. Affordable housing programs are measures to combat urban poverty and homelessness.

Special measures to ensure the environmental and climate sustainability of cities are not highlighted in the Rectangle Strategy. Building standards are written with the requirements of "quality, safety, beauty, efficiency and compliance with the principles of a smart city", however, environmental issues are not spelled out. The issue of energy supply without harming the environment is covered in the section - environmental sustainability. The need to "encourage and increase investment in clean energy and renewable energy" is mentioned. It applies to both urban and rural communities, but increased investment indicates a growing need for energy. In the Strategic Plan, the contribution of urban communities to solving environmental problems also includes "facilitating the planning and development of capital-intensive transport infrastructure" and "modernizing wastewater treatment plants and landfills," [24] which demonstrates the desire to begin creating an effective waste management system.

The "Rectangle Strategy" focuses on rural poverty and unemployment (41.5\%), which are proposed to be addressed by creating new jobs in the agricultural sector and increasing 
access to public services. As suggested in the strategy, this should lead to a reduction in inequality. However, no distinction is made between rural and urban poverty, and therefore there may be a problem with identifying the needs of recipients of targeted assistance and planning for creating jobs in cities.

\subsection{Myanmar}

Myanmar has implemented the Sustainable Development Goals into its Sustainable Development Plan 2018-2030 [25]. Within its framework, the sustainable development of cities is understood primarily as improving the quality of life of their residents and ensuring the ecological balance. Sustainable Development Goal No. 11 is not related to the national goal of peace, national reconciliation, security and good governance. This is due to the fact that the construction of an effective government system is seen as a derivative of national reconciliation achieved through real federalization, within the framework of which each individual ethnic group has the right to form its own models of civil society relations. Accordingly, achieving effective urban governance through communication between municipalities and civil society is a long-term issue.

However, in the Sustainable Development Plan, the objective of "strengthening urban governance mechanisms and related political mechanisms" is mentioned. However, this task is primarily associated with the fight against the vulnerability of certain population groups and urban poverty. The expansion of powers in the field of urban governance, according to the plan, should primarily ensure an equitable distribution of land resources, solve gender and youth problems of citizens. The latter points to the inherent diversification of vulnerable groups and the possibility of using targeted protective measures against them, despite the fact that poverty reduction measures are more relevant to rural areas. In this, Myanmar's strategy differs from Cambodian and partly from Bhutan's.

From the point of view of the set goals, the strategy for achieving the environmental sustainability of Myanmar's cities has been worked out more fully and holistically than the strategies of Bhutan and Cambodia. The goal of creating a waste collection and disposal system within the framework of responsible environmental management is specified, inclusion of expenses on the prevention and elimination of the consequences of natural disasters caused by climate change in the budgets of all levels (including cities), increasing the sustainability of urban infrastructure and services to protect against climate change and natural disasters provided. The task of increasing the share of renewable energy and expanding low-carbon transport networks relates indirectly to the same aspect, since it was urbanization that caused an increase in electricity demand in Myanmar.

\section{Conclusions}

The formation of sustainable cities in the least developed countries (there are 9 countries in Asia) is complicated by the lack of material resources in these countries for creating infrastructure and institutional levers of influence on local authorities and urban communities. As a result, the three main challenges leading to an imbalance in the construction of sustainable cities are:

- $\quad$ propensity for authorized agencies to use dirigiste methods without regard to urban communities;

- the tendency to ignore the solution to problems of population influx or environmental disturbance due to lack of funds; 
- focus on solving urban development problems in the short term, and not in the strategic long-term plan.

Based on the analysis of the three least developed countries' strategies for creating sustainable urban environments and communities, we conclude that these strategies reflect not only the sustainable development problems that are characteristic of the Asian region (urban poverty, lack of waste management systems, overload of transport systems), but also a global emphasis on solving these problems by building intra-urban networks of civil society and self-government. Namely, decentralization and "improving the efficiency and effectiveness of municipal services" in Bhutan, reliance on corporate social responsibility and "continuing the implementation of the public-private dialogue mechanism" in Cambodia, "strengthening urban governance mechanisms and related political mechanisms" in Myanmar. The second "pillar" of achieving urban sustainability, responsible consumption, in our opinion, is implemented in the tasks of developing the economic sector of information and computer technologies (Bhutan), promoting alternative energy and improving transport systems (Myanmar, Cambodia), waste management and expanding low-carbon transport networks (Myanmar). Moreover, the long-term task of building urban governance on the basis of civil society is aimed at creating a mechanism to solve the short-term problems of urban development in the least developed countries. Namely, urban poverty and ethnic conflicts in an urbanized environment, while the tasks of responsible consumption of services provided by urban infrastructure are aimed at achieving the long-term goal of balanced interaction with the environment. Since the strategists reflect the aspect of urban governance, and the aspect of achieving sustainable consumption, we consider the hypothesis that it is these aspects in the context of modern concepts that are considered drivers of sustainable urban development on a global scale, confirmed.

\section{References}

1. G. Haughton, C. Hunter, Sustainable cities Routledge, (2004)

2. J. Smit, Urban Agriculture: Food, Jobs, and Sustainable Cities, (2011)

3. D. Satterthwaite, Sustainable Cities or Cities that Contribute to Sustainable Development, Urban Stud., 34, 1667-1691,(1997)

4. B. Evans, M. Joas, S. Sundback, K. Theobald, Governing Sustainable Cities, (2005)

5. O. J. Ling, Sustainability and Cities: Concept and Assessment, (2005)

6. E. P. Trindade, M. P. F. Hinnig, E. Costa, E. S. Marques, R. C. Bastos, T. Yigitcanlar, Sustainable development of smart cities: a systematic review of the literature, Journal of Open Innovation: Technology, Market, and Complexity, 3(3), 74-89, (2017)

7. M. Höjer, J. Wangel, Smart Sustainable Cities: Definition and Challenges, ICT Innovations for Sustainability 5,333-349 (2014)

8. A. Kramersa, M. Höjera, N. Lövehagenb, J. Wangel, Smart sustainable cities Exploring ICT solutions for reduced energy use in cities, Environmental Modelling \& Software, 56, 52-62, (2014)

9. Sustainable Development Goals, (2019). https://kidb.adb.org/kidb/sdg

10. M. Ermolina, A. Matveevskaya, S. Pogodin, Efficiency of the un action in the area of transport, environmental protection, health, MATEC Web Conf 239,04016, (2018). DOI: $10.1051 /$ matecconf $/ 201823904016$ 
11. H. Bulkeley, M. Betsill, Rethinking Sustainable Cities: Multilevel Governance and the 'Urban' Politics of Climate Change, Environ Polit, 42-63, (2010)

12. A. Matveevskaya, S. Pogodin, Integration of migrants as a way to diminish proneness to conflict in multinational communities, Vestnik of Saint Petersburg University. Philosophy and Conflict Studies, 34(1), 108-114, (2018). DOI: 10.21638/11701/spbu17.2018.110

13. R. Bolgov, S. Bogdanovich, V. Yag'Ya, M. Ermolina, How to measure the digital diplomacy efficiency: Problems and constraints, Communications in Computer and Information science,674, 180-188, (2016). DOI: 10.1007/978-3-319-49700-6_18

14. M. Strauss, When Malthus Meets Mendel, Foreign Policy, 119, 105-112, (2000)

15. Sustainable Cities in Asia, https://www.taylorfrancis.com/books/9781315643069

(2017).

16. T. Yigitcanlar, Md. Kamruzzaman, Does smart city policy lead to sustainability of cities? Land Use Policy, 73, 49-58, (2018)

17. M. Lindfield, Challenges for Sustainable Urban Development in Asia, (2016). http://www.adb-asianthinktanks.org/sites/all/libraries/2016ATTN/2016-

Presentations/Delhi\%20Forum\%20Sustainable\%20Urbanisation\%20M.Lindfield\%20O ctober\%202016.pdf

18. Green Cities, (2019). https://www.adb.org/green-cities/index.html

19. J. R. Kenworthy, Is Automobile Dependence in Emerging Cities an Irresistible Force? Perspectives from São Paulo, Taipei, Prague, Mumbai, Shanghai, Beijing, and Guangzhou, Sustainability-Basel, 9(11), 423-438, (2017)

20. The Future of Asian and Pacific Cities 2019: Transformative Pathways Towards Sustainable Urban Development, (2019). https://www.unescap.org/publications/futureasian-and-pacific-cities-2019-transformative-pathways-towards-sustainable-urban

21. T. Kikuchi, World Bank says $64 \%$ of people who live in slums are in Asia, Nikkei. Asian Review, (2017). https://asia.nikkei.com/Economy/World-Bank-says-64-ofpeople-who-live-in-slums-are-in-Asia

22. Employment in Asia-Pacific continues to grow but often remains of poor quality, (2019) https://www.ilo.org/asia/media-centre/news/WCMS_615872/lang-en/index.htm

23. Twelfth Five-Year Plan. 2018-2023, (2019). https://www.gnhc.gov.bt/en/wpcontent/uploads/2019/05/TWELVE-FIVE-YEAR-WEB-VERSION.pdf

24. Rectangular Strategy-Phase 4 of Samdech Techo HUN SEN, (2019) http://cnv.org.kh/wp-content/uploads/2012/10/Rectangular-Strategy-Phase-IV-of-theRoyal-Government-of-Cambodia-of-the-Sixth-Legislature-of-the-National-Assembly2018-2023.pdf

25. Myanmar Sustainable Development Plan (2018 - 2030), (2019) https://themimu.info/sites/themimu.info/files/documents/Core_Doc_Myanmar_Sustain able Development_Plan_2018_2030_Aug2018.pdf 